\title{
A RELIGIÃo E SUA RELAÇÃO COM A CONSTITUIÇÃO DE IDENTIDADES HOMOSSEXUAIS
}

\author{
Dra. Andréa Forgiarini Cecchin 0000-0001-6945-9731 \\ Universidade Federal de Santa Maria
}

\begin{abstract}
RESUMO: Em uma pesquisa sobre a relação entre as vivências em espaços educativos e a constituição de identidades homossexuais, a religião surge como um elemento importante para análise deste fenômeno. O estudo apoiase teoricamente nas contribuições da Psicologia Social Crítica e adota a Análise Compreensiva de Base Fenomenológica como abordagem metodológica. Foram entrevistados oito sujeitos homossexuais, selecionados a partir da técnica snow ball sampling. As questões formuladas focalizavam percepções e sentimentos desses sujeitos em relação a si próprios e aos outros, considerando suas vivências nesses espaços educativos e,
\end{abstract}

especialmente, suas experiências de discriminação e resistência. A religiosidade apresentou-se como uma das temáticas emergentes. Os sujeitos que tiveram uma rigorosa formação religiosa corroboraram a suposição de que homossexuais que cresceram em ambientes nos quais a religião tem presença marcante tendem a internalizar, mais intensamente, valores negativos em relação à sua orientação afetivo-sexual. A convivência, desde a infância, com representações implícitas e explícitas de oposição à homossexualidade, afeta a autoestima e a aceitação de si dessas pessoas torna-se conflituosa.

PALAVRAS-CHAVE: homossexualidade; religião; identidade.

\section{RELIGION AND ITS RELATIONSHIP WITH THE CONSTITUTION OF HOMOSEXUAL IDENTITIES}

\begin{abstract}
In a research about the relationship between the experiences in educational spaces and the constitution of homosexual identities, religion appears as an important element for the analysis of this phenomenon. The study is based theoretically on the contributions of Critical Social Psychology and adopts the Comprehensive Analysis of Phenomenological Basis as a methodological approach. Eight homosexual subjects, selected using the snow ball sampling technique, were interviewed. The questions formulated focused on the perceptions and feelings of these subjects in relation to themselves and to others, considering their experiences in these
\end{abstract}

educational spaces and especially their experiences of discrimination and resistance. Religiosity was one of the emergent themes. The subjects who had a rigorous religious formation corroborated the assumption that homosexuals who grew up in environments in which religion has a marked presence tend to internalize, more intensely, negative values in relation to their affective-sexual orientation. Coexistence, from childhood, with implicit and explicit representations of opposition to homosexuality, affects self-esteem and the self-acceptance of these people becomes conflicted. 


\section{Educere "Educare \\ Revista de EduCAČ̃̃o}

Programa de Pós-Graduação em Educação - Universidade Estadual do Oeste do Paraná

\section{INTRODUÇÃO}

Até o século XVIII, os homossexuais eram tratados pela Igreja como sodomitas, uma categoria bastante ampla, pois incluía contatos sexuais (não necessariamente anais) entre homens, homens e animais, ou homens e mulheres, desafiando a reprodução (BADINTER, 1993). Por motivos religiosos, a sodomia era proibida, considerada um pecado muito grave. Nos séculos anteriores, a Inquisição punira severamente os sodomitas. Os castigos variavam desde trabalhos forçados, degredo para países distantes, confisco de bens, multas em dinheiro, açoites até a famosa fogueira (TREVISAN, 2002). Para Nunan (2003) o que definia os sodomitas eram os seus comportamentos, não suas inclinações (heterossexuais ou homossexuais). Essa autora esclarece:

O indivíduo que tinha o desejo de praticar sodomia, mas não o fazia, não era considerado um sodomita. Da mesma forma, aquele que abandonasse o vício abominável deixava, igualmente, de ser taxado (sic) de sodomita. Em outras palavras, a categoria era definida pelo ato, não pelo indivíduo que o praticasse. O sodomita não tinha, tal como aconteceria mais tarde com o homossexual, uma fisiologia ou psicologia particular (NUNAN, 2003, p. 33).

De pecado, a sodomia evolui para crime contra o Estado. Segundo Trevisan (2002), nas Ordenações Filipinas (1603/1867) - uma das compilações jurídicas portuguesas que vigorou no Brasil por mais de dois séculos, determinava-se que o sodomita fosse queimado e seus bens confiscados pela Coroa, independente dessa pessoa ter descendentes ou não, pois essa era uma forma de difamar também a descendência daqueles que praticavam a sodomia. Em 1830, foi sancionado o Código Criminal Brasileiro. Nesse documento, de inspiração napoleônica, a figura jurídica da sodomia é eliminada. No entanto, surgem os crimes "por ofensa à moral e aos bons costumes" quando praticados em público. Nos Códigos Penais que se seguiram (1890 e 1940) a figura jurídica permanece a mesma, agora sob o nome de "crime contra a segurança da honra e honestidade das famílias", ou "ultraje público ao pudor", ou "atentado violento 


\section{Educere Educare \\ ReVISTA DE EduCACÃ̃o}

Programa de Pós-Graduação em Educação - Universidade Estadual do Oeste do Paraná

ao pudor". Sem qualquer menção explícita, foi sob tais infrações que a homossexualidade foi enquadrada (TREVISAN, 2002).

Até meados do século XIX, um dos termos utilizados para designar sujeitos homossexuais era invertido, sugerindo que todo homossexual era "feminino", portador de uma inversão sexual. Em 1862, o jurista alemão Karl Heinrich Ulrichs através do termo uranismo introduziu a noção de um terceiro sexo - uma "mente de mulher num corpo masculino" e vice-versa, com a intenção de provar que a homossexualidade era uma inclinação natural e, portanto, legítima (TREVISAN, 1997). A palavra uranismo deriva de Afrodite Urânia, a musa que, no discurso de Pausânias, no Banquete de Platão, representava o amor entre homens (NUNAN, 2003).

De acordo com Trevisan (2002), o termo "homossexual" utilizado pela primeira vez em 1869, marca os esforços dos estudiosos da época em definir com rigor científico as características da sexualidade vista como desviante. A introdução do conceito de "homossexual" marca uma divisão histórica na maneira como as práticas homossexuais passaram a ser encaradas ao longo do tempo nas sociedades ocidentais. O pensamento de Badinter (1993) ilustra bem essa situação

O sodomita, que era apenas uma aberração temporária, dá lugar ao "homossexual", que caracteriza uma espécie particular. Com a invenção de novas palavras - "homossexual" e "invertido" - para designar aqueles que se interessam pelo mesmo sexo, altera-se a idéia que se faz deles. A criação de uma palavra corresponde, neste caso, à criação de uma essência, de uma doença psíquica e de um mal social. O nascimento do "homossexual" é o nascimento de uma problemática e de uma intolerância que sobreviveram até os nossos dias (BADINTER, 1993, p.102).

$\mathrm{Na}$ época em que eram considerados sodomitas, esses sujeitos eram vistos como pecadores, em seguida foram considerados criminosos, passando a ser encarados como inimigos do Estado. À medida que passaram a ser definidos como homossexuais, no final do século XIX, sua condição muda, e eles passam a ser vistos como anormais. 


\section{Educere "Educare \\ Revista de EduCAČ̃̃o}

Programa de Pós-Graduação em Educação - Universidade Estadual do Oeste do Paraná

A partir do momento em que a homossexualidade passa a ser vista como um desvio de comportamento, como uma patologia, surgem inúmeras tentativas de "cura" do sujeito homossexual. Propõe-se a abstinência forçada e a hipnose na expectativa de convencer esses indivíduos a desejarem sexualmente uma mulher (NUNAN, 2003). Paralelo a isto, estabelecesse a normalidade heterossexual: a sexualidade masculina "normal" estaria vinculada a um "instinto" cujo objeto natural seria o sexo oposto. $\mathrm{O}$ conceito de heterossexualidade é criado para descrever essa normalidade, postulando uma diferença radical entre os sexos e ligando de modo indissolúvel a identidade de gênero (ser um homem ou uma mulher) e a identidade sexual (BADINTER, 1993).

Em um estudo que tinha por objetivo investigar as relações que se podem estabelecer entre as vivências em espaços educativos e a constituição de identidades homossexuais, uma das temáticas emergentes foi a influência da religião na construção destas identidades (CECHIN 2006; CECCHIN, 2016). Esse artigo tem a preocupação de aprofundar os achados daquela investigação buscando compreender como a moral religiosa afetou a forma como esses sujeitos vivenciavam sua sexualidade e sentiam-se a respeito de sua orientação afetivo-sexual. Parte-se do entendimento que "a concepção de cada religião sobre o tema poderá influenciar a vida de pessoas de orientação homossexual, que podem aceitá-la ou então buscar uma "cura" ou resolução para o "problema" (RIBEIRO e SCORSOLINI-COMIN, 2017, p. 02). De toda forma, pelo que se pode observar, as doutrinas religiosas impactaram a construção da identidade dos participantes desta investigação.

Os sujeitos deste estudo foram oito homens adultos que se identificavam como homossexuais. A seleção desses indivíduos foi feita pela técnica denominada snowball sampling (amostragem por "bola de neve"), na qual um sujeito indica outro participante, que indica outro e assim por diante. 


\section{Educere Educare \\ ReVISTA DE EduCACÃ̃o}

Programa de Pós-Graduação em Educação - Universidade Estadual do Oeste do Paraná

Para coleta dos dados, utilizou-se a entrevista individual e por tópicos. Lüdke e André (1986) afirmam que esta é uma das principais técnicas de coleta de dados em quase todos os tipos de pesquisa utilizados nas Ciências Sociais e na Educação. De acordo com essas autoras, é fundamental estar atento para o caráter de interação que permeia essa técnica. Segundo elas,

[...] na entrevista a relação que se cria é de interação, havendo uma atmosfera de influência recíproca entre quem pergunta e quem responde. Especialmente nas entrevistas não totalmente estruturadas, onde não há a imposição de uma ordem rígida de questões, o entrevistado discorre sobre o tema proposto com base nas informações que ele detém e que no fundo são a verdadeira razão da entrevista (LÜDKE e ANDRÉ, 1986, p. 33).

$\mathrm{Na}$ perspectiva dessas autoras, a vantagem de se realizar a entrevista é que ela permite a captação imediata da informação desejada, permitindo correções, esclarecimentos e adaptações.

Os dados obtidos foram analisados de acordo com o método da Análise Compreensiva de Base Fenomenológica, proposto por Bernardes (1989, 1991). Essa abordagem fundamenta-se no pensamento filosófico fenomenológico, principalmente de Merleau-Ponty (1971) e opera com o método fenomenológico psicológico proposto por Giorgi $(1978,1985,2001)$ e com a sistematização elaborada por Suransky (1977), para realizar a aproximação do mundo da vida dos sujeitos e compreender a articulação entre os horizontes externos e internos da experiência (BERNARDES, 1989).

\section{IDENTIDADE NA PERSPECTIVA DA PSICOLOGIA SOCIAL}

Neste campo da Psicologia Social, a temática da identidade vem sendo focalizada desde o início do século passado. Após um período de poucos avanços, o tema voltou a receber atenção em trabalhos que tratam sobre relações entre grupos, sobre diferenciação social e sobre identidade marginal (JACQUES, 1998). 


\section{Educere Educare \\ ReVISTA DE EduCACÃ̃o}

Programa de Pós-Graduação em Educação - Universidade Estadual do Oeste do Paraná

De acordo com Jacques (1998), o conceito de identidade tem sido denominado por meio de diferentes expressões tais como imagem, representação e conceito de si: refere-se a conteúdos como conjuntos de traços, de imagens, de sentimentos que o sujeito reconhece como fazendo parte dele próprio. Enquanto na literatura norte-americana o termo consagrado é "self" ou "self-concept", correspondendo a conceito de si, a tradição europeia privilegia a noção de representação de si. A autora explica:

A identidade pode ser representada pelo nome, pelo pronome eu ou por outras predicações como àquelas referentes ao papel social. No entanto, a representação de si através da qual é possivel apreender a identidade é sempre a representação de um objeto ausente (o si mesmo). Sob este ponto de vista, a identidade se refere a um conjunto de representações que responde a pergunta 'quem és' (JACQUES, 1998, p. 161).

Essas diferentes terminologias refletem não só uma diversidade teóricometodológica como também a complexidade que este envolve. Um dos reflexos dessa dificuldade conceitual é a subdivisão dos sistemas identificatórios, assim a identidade é qualificada como identidade pessoal (atributos específicos do indivíduo) e identidade social (atributos que assinalam o pertencimento a grupos ou categorias) (JACQUES, 1998).

A identidade de um indivíduo se constitui a partir do contexto histórico e social em que está inserido. Daí decorrem, como formas histórico-sociais de individualidade, as possibilidades e impossibilidades, os modos e alternativas de sua identidade. Como determinada, a identidade se configura, ao mesmo tempo, como determinante, pois o sujeito tem um papel ativo na construção deste contexto, tanto pela inserção quanto pela apropriação que faz do mesmo (JACQUES, 1998). A partir desta perspectiva

[...] é possivel compreender a identidade pessoal como e ao mesmo tempo identidade social, superando a falsa dicotomia entre essas duas instâncias. Dito de outra forma: o individuo se configura ao mesmo tempo como personagem e autor - personagem de uma história que ele mesmo constrói e que, por sua vez, o vai construindo como autor (JACQUES, 1998, p. 163). 


\section{Educere Educare \\ ReVISTA DE EduCAC̄̃̃o}

Programa de Pós-Graduação em Educação - Universidade Estadual do Oeste do Paraná

Ao pensar a identidade, não como algo estático, mas como algo dinâmico, em constante mutação, Ciampa (2001) concebe a identidade como metamorfose. Segundo esse autor, cada indivíduo encarna as relações sociais, configurando uma identidade pessoal, uma história de vida, um projeto de vida que pode ou não se concretizar, no emaranhado das relações sociais. Ao mesmo tempo em que constituem a sociedade, as identidades são por ela constituídas.

Num primeiro momento, a tendência é analisar a identidade como um traço estático na definição do sujeito. $O$ indivíduo aparece isolado, sua identidade surge como algo imediato, imutável. Geralmente, essa representação é feita pelo nome próprio (CIAMPA, 2001). No entanto, embora nos represente, "o nome próprio é uma representação da identidade precocemente adquirida a partir da forma como os outros nos chamam e, portanto, pelo seu caráter restritivo não dá conta da identidade" (JACQUES, 1998, p. 165).

O nome nos identifica e passamos a nos identificar com ele. Se, no início, os outros me chamavam por um nome que me foi dado, agora "eu me chamo...", identifico-me por fulana de tal. Nós "interiorizamos aquilo que os outros nos atribuem de tal forma que se torna algo nosso. A tendência é nós nos predicarmos coisas que os outros nos atribuem" (CIAMPA, 2001, p. 131). Assim, nos tornamos filhos de fulano, netos de sicrano, alunos, sobrinhos... Assumimos papéis que vão constituindo nossa identidade.

Essa predicação também envolve a orientação religiosa que recebemos desde a infância. Mesmo aqueles indivíduos que não se consideram religiosos, se identificam como pertencentes a esta ou aquela afiliação religiosa por terem sido educados nesta ou naquela fé.

\section{A RELIGIÃO E A CONSTITUIÇÃO DA IDENTIDADE HOMOSSEXUAL}




\section{Educere "Educare \\ Revista de EduCAČ̃̃o}

Programa de Pós-Graduação em Educação - Universidade Estadual do Oeste do Paraná

Assim como Nunan (2007) em seu estudo sobre preconceito sexual internalizado, percebeu-se neste estudo que homossexuais religiosos internalizavam mais atitudes negativas em relação à sua orientação afetivosexual do que aqueles que não praticavam religião alguma. Constatou-se, também, que aqueles sujeitos que tiveram uma formação religiosa muito rigorosa na infância e adolescência vivenciaram um conflito maior para se assumirem, para si e para os outros, como homossexuais.

Ao discutir a relação entre preconceito e religião, Myers (2000) reflete que é dificil estabelecer a relação causal entre essas duas variáveis. É admissivel que as pessoas com menor escolaridade sejam mais fundamentalistas e mais preconceituosas. Também é possivel que o preconceito conduza à religião, levando as pessoas a desenvolverem ideias religiosas para justificarem suas atitudes preconceituosas. Há, ainda, a possibilidade de a religião induzir ao preconceito, ao fazer as pessoas acreditarem que Deus dotou todos os seres humanos com livre arbitrio e que os homossexuais não podem culpar ninguém, a não ser a si próprios, por sua situação. No entanto, a explicação de que a Bíblia condena a homossexualidade não faz muito sentido, já que a Bíblia postula outras condenações para as quais não damos importância.

A maioria dos sujeitos deste estudo teve, em algum momento de suas vidas, contato com a doutrina da Igreja Católica: Dois deles receberam apenas o batismo, outros três tiveram uma formação mais abrangente. Com exceção de um deles, com o tempo, todos abandonaram por completo essa religião. Isso provavelmente ocorreu devido à posição dessa Igreja em relação à homossexualidade. A doutrina da Igreja Católica orienta que não se pode discriminar um sujeito por sentir atração pelo mesmo sexo, o condenável são os atos sexuais. Dessa forma, o desejo tem de ficar no nível platônico e nunca se concretizar.

O Catecismo da Igreja Católica distingue entre atos homossexuais e tendências homossexuais. Ensina que, na Sagrada Escritura, os atos 


\section{Educere Educare \\ ReVISTA DE EduCACÃ̃o}

Programa de Pós-Graduação em Educação - Universidade Estadual do Oeste do Paraná

homossexuais são apresentados como pecados graves. A Tradição considerou-os constantemente como intrinsecamente imorais e contrários à lei natural. Consequentemente, não podem ser aprovados em caso algum. As tendências homossexuais profundamente radicadas, existente em certo número de homens e mulheres, são objetivamente desordenadas e constituem, frequentemente, uma provação para essas pessoas. As pessoas que têm apenas tendência devem ser acolhidas com respeito e delicadeza, evitando-se, em relação a elas, qualquer marca de discriminação injusta. "Essas pessoas são chamadas a realizar na sua vida a vontade de Deus e a unir ao sacrificio da cruz do Senhor as dificuldades que possam encontrar" (CATECISMO DA IGREJA CATÓLICA, 1993).

Para essa religião, mesmo que exista o sentimento, é necessário reprimir o desejo, já que a relação sexual entre dois homens ou duas mulheres é considerada pecado. De acordo com Silveira (2006), a moral cristã considera ainda a conversão dessas pessoas. Por uma questão ética, ou politicamente correta, não se fala mais em cura da homossexualidade. Mas o Catecismo traz que:

As pessoas homossexuais são chamadas à castidade. Pelas virtudes de autodomínio, educadoras da liberdade interior, às vezes pelo apoio de uma amizade desinteressada, pela oração e pela graça sacramental, podem e devem se aproximar, gradual e resolutamente, da perfeição cristã (CATECISMO DA IGREJA CATÓLICA, 1993).

De acordo com este excerto, a sublimação do desejo é o que pode levar o indivíduo homossexual à perfeição cristã. Em outros trechos, fica claro que, para a Igreja Católica, a relação sexual entre pessoas do mesmo sexo contraria a "lei natural", pois "fecham o ato sexual ao dom da vida" (CATECISMO DA IGREJA CATÓlICA, 1993). Ao definir que a procriação é a principal função da sexualidade, o catolicismo passa a considerar como ilegitimas as práticas sexuais que não tem essa intenção e orienta seus seguidores a reprimi-las (SILVA, 2012). 


\section{Educere Educare \\ ReVISTA DE EdUCACÃ̃o}

Programa de Pós-Graduação em Educação - Universidade Estadual do Oeste do Paraná

No ponto de vista de Ranke-Heinemann (1999), na maioria das religiões cristãs a associação do sexo ao pecado ainda é uma realidade. As pessoas que apresentam uma sexualidade que, segundo essas doutrinas, foge a normalidade são consideradas pecadoras e precisam expiar seus pecados através da confissão, da penitência, da renúncia ao desejo considerado proibido. Por conta desta crença, muitos homossexuais, considerados "sodomitas" foram perseguidos e mortos durante a Inquisição. Não resta dúvida de que "um dos grandes formadores de homofobia foram as religiões, que por sua vez auxiliaram a ditar as normas de gênero. As crenças religiosas foram os primeiros "códigos de conduta" oficiais criados pelos povos desde os tempos mais antigos" (ANTUNES, 2016, p. 157).

A realizar um estudo sobre homofobia internalizada, Antunes (2016) que investigou, entre outras coisas, as percepções de 422 integrantes da comunidade LGTB sobre religião e sexualidade, constatou que "religiões conservadoras provocavam altos níveis de vergonha, culpa e homofobia internalizada" (ANTUNES, 2016, p. 159).

Antes de abandonar a Igreja Católica, um dos entrevistados, além do batismo, fez catequese por cinco anos e chegou a iniciar a preparação para a Crismai. Não procurou outra religião, afirmava estar abstêmio de Deusii, acreditava que Este virou-lhe as costas. Pelo tom de mágoa de sua declaração, pode-se deduzir que ele acreditava que Deus o tinha abandonado por ser homossexual. Coincidência ou não, dos sujeitos da pesquisa, este era um dos que ainda ocultava da família sua orientação afetivo-sexual, confirmando que "Gays que internalizam estas crenças podem se sentir inferiores aos heterossexuais e incapazes de alcançar objetivos que contradigam o preconceito" (NUNAN, 2007, p. 91).

A formação católica de outro sujeito foi ainda mais abrangente: fez primeira comunhão, Crisma, foi coroinha, participou de grupos de oração e estudou em escolas confessionais durante toda a Educação Básica. Durante a 


\section{Educere "Educare \\ ReVISTA DE EduCAČ̃̃o}

Programa de Pós-Graduação em Educação - Universidade Estadual do Oeste do Paraná

adolescência, vivenciou um conflito religioso muito grande por ser gay: ouvia que ser homossexual era algo ruim, pecaminoso, do mal. Embora não sentisse que estivesse fazendo algo ruim, sofreu e se penitenciou:

Porque a gente tinha um grupo de oração que eles incutiam uma coisa como se fosse uma coisa ruim, uma coisa pecaminosa, uma coisa do mal.

Eu via que era uma coisa que me deixava bem, que me deixava feliz. Então eu pensava "como é que pode ser uma coisa ruim? Como é que pode ser uma coisa pecaminosa isto?". No começo sim porque tinha aquele grupo de oração que "Ah! Tu ta fazendo pecado! Ah! Não sei o quê". Dai eu comecei a me culpar, sabe?

No colégio tinha um morro lá que nós tínhamos que colher cana, pasto... nem o tratorzinho subia naquele morro. E nós fomos colher feixes de cana $e$ tinha que descer aquele morro enorme. Ai a gente vinha descendo carregando aqueles feixes de cana e eu pensando, me culpando, aquela coisa "Ah! Eu estou como Jesus que carrega sua cruz e não sei o que", sabe? "Eu tenho que sofrer para pagar os meus pecados".

A internalização dos preceitos da religião pode ser tão intensa que a pessoa passa a sofrer do que alguns autores (NUNAN, 2007; ANTUNES, 2016) chamam de homofobia internalizada. Nessa perspectiva, "o preconceito internalizado se apresenta em um contínuo que vai desde questionamentos sobre seu próprio valor como indivíduo até o ódio por si mesmo" (NUNAN, 2007, p. 93).

Num determinado momento, esse indivíduo questionou quais eram mesmo os seus pecados e concluiu que não precisava se punir, pois não sentia que ser homossexual era errado. Observou que havia heterossexuais que apresentavam um comportamento muito mais condenável que o seu - agrediam, brigavam, eram maus com as pessoas - e nem por isso eram considerados pecadores como ele. Parou de se culpar e passou a encarar sua homossexualidade como uma coisa boa, como algo que o fazia feliz. Admitiu seguir os preceitos de todas as religiões, pois acreditava que uma pessoa do bem poderia transitar por todas as religiões sem problemas. Ao abordar essa questão, Nunan (2007) traz que as pessoas que desenvolvem um sentido de espiritualidade desvinculado ao de uma religião formal são "capazes de mediar os efeitos negativos do preconceito 


\section{Educere Educare \\ ReVISTA DE EduCACÃ̃o}

Programa de Pós-Graduação em Educação - Universidade Estadual do Oeste do Paraná

religioso em suas vidas, superando o aparente conflito entre homossexualidade e religiosidade, e caminhando em direção à aquisição de uma identidade gay mais positiva" (NUNAN, 2007, p. 331).

Este entrevistado comentou que um dos motivos que fez com que deixasse de se sentir um pecador por ser gay foi a percepção de que muitos daqueles religiosos que condenavam sua homossexualidade também eram homossexuais. Embora seja de conhecimento geral que existem homossexuais no clero, a Igreja Católica nada faz para compreender o desejo desses indivíduos. Em 2005, o Papa Bento XVI publicou um documento denominado "Instrução sobre os Critérios de Discernimento Vocacional Acerca das Pessoas com Tendências Homossexuais e da sua Adesão ao Seminário e às Ordens Sacras”, determinando que a Igreja "não pode admitir ao Seminário e às Ordens sacras aqueles que praticam a homossexualidade, apresentam tendências homossexuais profundamente radicadas ou apoiam a chamada cultura gay" (VALLE, 2006, p. 170). Esse documento abre uma exceção

[...] no caso de se tratar de tendências homossexuais que sejam apenas expressão de um problema transitório como, por exemplo, o de uma adolescência ainda não completa, elas devem ser claramente superadas, pelo menos três anos antes da Ordenação diaconal (VALLE, 2006, p. 170).

A própria política dessa Igreja em relação à sexualidade é bastante retrógrada: admite apenas sexo para procriação (ou seja, relações heterossexuais) e é contra o uso de preservativos, uma das atitudes mais questionadas em tempos de AIDS. Essa postura tem origem no pensamento finalista de Aristóteles e essencialista de Platão que influenciaram os escritos de São Paulo, Santo Agostinho e São Tomás de Aquino. Para eles, os órgãos reprodutivos eram naturalmente destinados a procriação e qualquer utilização para outro propósito, como por exemplo, a satisfação do desejo sexual, era condenável (ANTUNES, 2016). 


\section{Educere Educare \\ ReVISTA DE EduCACÃ̃o}

Programa de Pós-Graduação em Educação - Universidade Estadual do Oeste do Paraná

Outro sujeito da pesquisa criticou o catolicismo por seu preconceito com os homossexuais e por sua intransigência em relação à contracepção. Chamava a Igreja Católica de hipócrita por ter conhecimento de que existem homossexuais no clero e, ainda assim, condenar veementemente os gays. Assim como outro entrevistado, apesar de ter sido educado na religião católica, na adultez migrou para uma religião de Matriz Africana:

\footnotetext{
Em geral, os sujeitos que optaram pelo candomblé o fizeram em momentos posteriores de suas vidas, visto que ambos foram criados dentro do catolicismo. Entre as razões para a identificação com esta religião foram citados: a inexistência de idéia de pecado ou culpa, a visão de liberdade (cada indivíduo sabe se está fazendo o "bem" ou o "mal", e o que é bom para si) e a dualidade dos deuses (NUNAN, 2003, p. 210).
}

Autores como Fry (1983), Green (2000) e Nunan (2003) apontam que essas religiões são mais tolerantes com a homossexualidade. Além disso, de acordo com Green (2000) tais práticas religiosas oferecem um relativo espaço social para muitos homossexuais de origem humilde. Fry (1983) corrobora esta ideia ao constatar que, no Nordeste, a grande maioria dos pais e mães-de-santo são homossexuais. Explica que não é raro casos de meninos e meninas que são discriminados em casa por sua orientação afetivo-sexual encontrarem nessas comunidades religiosas um lugar onde são aceitos. Comenta que não é raro que essas pessoas, depois de conseguirem destaque dentro da religião, sejam aceitas pelos seus parentes pelo prestígio religioso que alcançaram. De acordo com autor, "o candomblé, então, oferece a possibilidade de um jovem rapaz ou menina homossexual transformar seu estigma social em vantagem" (FRY, 1983, p. 54).

Ao contrário dos sujeitos que ingressaram nessa religião depois de adultos, um dos entrevistados acreditava ser de uma religião de Matriz Africana por uma questão cultural: herdou essa formação de seus ancestrais. Inclusive, ele e seu companheiro eram líderes religiosos com uma significativa projeção na comunidade. 


\section{Educere "Educare \\ Revista de EduCAČ̃̃o}

Programa de Pós-Graduação em Educação - Universidade Estadual do Oeste do Paraná

Ao analisar o item religião numa pesquisa que procurou traçar o perfil dos participantes da 9a Parada do Orgulho GLBT, realizada no Rio de Janeiro, em 2004, constatou-se o caráter excludente das religiões cristãs em relação à homossexualidade. De acordo com os dados, esses sujeitos acabam aderindo cada vez mais às religiões afro-brasileiras ou abandonando qualquer tipo de prática religiosa (CARRARA; RAMOS, 2005).

Dois sujeitos do estudo tinham em comum a influência da Igreja Evangélica em suas vidas, embora nenhum dos dois tenha sido batizado nessa religião.

O primeiro dizia acreditar em Deus, mas não se considerava uma pessoa religiosa, afirmava não ter despertado para esse mundo religioso. Sua mãe era evangélica e, ao saber da orientação afetivo-sexual do filho, tentou convertê-lo. Ela acreditava que Deus poderia modificar a orientação afetivo-sexual do rapaz e rezava para que ele se transformasse num heterossexual. Para os adeptos das religiões evangélicas, a homossexualidade é passivel de cura "através de terapias apropriadas, ministradas por profissionais especializados" (SILVA, 2012, p. 116). A crença na "reversão" da homossexualidade já causou muito sofrimento. O que se percebe é que o homossexual, a partir de um determinado tratamento ou culto de libertação, acaba por ocultar sua identidade sexual e, consequentemente, reprimir seu desejo, em nome da aceitação de um grupo.

Com o outro sujeito a situação era um pouco diferente, ele cresceu frequentando os cultos da Igreja Evangélica. Toda sua família professava essa religião: tinha um cunhado que era pastor e os sobrinhos participavam do coral da Igreja. A maioria das pessoas com que sua família se relacionava era da comunidade evangélica. Relatou que, apesar de ter conhecido outras religiões, o Deus que conheceu através da Bíblia e em quem tem fé é o Deus da Igreja Evangélica. Falava que os princípios dessa religião, a doutrina, estavam sempre com ele e procurava colocá-los em prática diariamente. Apesar de não ser 


\section{Educere "Educare \\ ReVISTA DE EduCACÃo}

Programa de Pós-Graduação em Educação - Universidade Estadual do Oeste do Paraná

evangélico praticante, visitava o templo e ouvia os hinos sempre que tinha oportunidade.

Um dos motivos que fez com que esse rapaz abandonasse a Igreja foi assumir sua homossexualidade. Disse ter se retirado da Igreja sem explicar o porquê, para não criar polêmica. Demorou bastante para se assumir, só o fazendo quando não podia mais "conter-se": Declarou: "E eu pensava: 'Nunca vou assumir, eu não quero ser isso. Eu quero ser homem, eu vou casar e...' sabe?” $\mathrm{Na}$ época da pesquisa ainda tinha dificuldades de aceitar o chamado "mundo gay", insistia em relacionar-se amorosamente com heterossexuais, colocava seus amigos heterossexuais num patamar superior aos amigos gays e era bastante preconceituoso com homossexuais afeminados e travestis. A negação pode aparecer em situações como esta para minimizar o sofrimento psíquico que essa realidade pode ocasionar. Para Nunan (2007) este mecanismo de defesa é muito efetivo, especialmente em casos de homossexuais com preconceito internalizado. Segundo esta autora:

Para muitas pessoas, apenas contemplar a possibilidade remota de que ela possa se sentir atraída por outras do mesmo sexo é tão perigosa e aterrorizante que a negação é a única saída psíquica que ela encontra para lidar com estes sentimentos "inaceitáveis" (NUNAN, 2007, p. 97).

Fica claro o sentimento de culpa que perpassa alguns indivíduos entrevistados neste estudo por não terem dado conta de negar sua homossexualidade. As igrejas, especialmente as evangélicas, adotam uma postura de acolhimento, mas de uma pessoa que, para sua doutrina, está perdida, desencontrada. Natividade e Oliveira (2009) chamam essa atitude de "homofobia pastoral" e explicam:

Estratégias convergentes com a homofobia cordial, mas dotadas de efeitos muito distintos, costumam comparecer em práticas religiosas voltadas para o cuidado pastoral junto a fiéis. Uma forma particularmente insidiosa de homofobia pastoral poderia ser identificada na perspectiva evangélica de "acolhimento" aos homossexuais, sustentada por certas iniciativas religiosas, que incorpora pessoas LGBT aos cultos, visando ao seu engajamento em um projeto de regeneração moral, pela libertação do homossexualismo. Esta atitude perante a diversidade sexual transcende os efeitos da homofobia cordial, na medida em que não apenas incorpora 


\section{Educere "Educare \\ Revista de EduCAČ̃̃o}

Programa de Pós-Graduação em Educação - Universidade Estadual do Oeste do Paraná

sujeitos marcados como inferiores, mas pretende eliminar tal "marca" por meio de "exorcismos", cura ou terapias (NATIVIDADE e OLIVEIRA, 2009, p. 129).

Não parece ser relevante discutir aqui qual religião é a mais homofóbica. No entanto, há que se sinalizar que, em virtude da expansão das discussões acerca da sexualidade, dos direitos sexuais, do respeito à comunidade LGBT,

[...] o tema da exclusão da diversidade sexual pelas religiões despontou, por meio de uma crítica à homofobia supostamente presente na tradição cristã e à consequente vinculação de tal prática sexual ao tema do pecado, da "abominação", da antinatureza (NATIVIDADE, 2010, p. 92).

Neste contexto, começam a despontar outras religiões, especialmente protestantes, que incluem os homossexuais e os respeitam em suas singularidades. Esse movimento alcançou o catolicismo, principalmente através do Papa Francisco que, em suas manifestações, desmistifica a ideia do homossexual pecador.

\section{CONSIDERAÇÕES FINAIS}

No que tange a religião, à exceção das religiões de matriz africana, grande parte das igrejas condena a homossexualidade, considerando o homossexual uma pessoa pecadora, cuja alma está doente e pode, através de resignação, penitência e oração, converter-se à heterossexualidade. Alguns sujeitos deste estudo que tiveram uma rigorosa formação religiosa corroboraram a suposição de que homens homossexuais que cresceram em ambientes nos quais a religião tem presença marcante tendem a internalizar, mais intensamente, valores negativos em relação à sua orientação afetivo-sexual.

Nesse cenário, o preconceito foi e continua sendo vivenciado pelos sujeitos deste estudo e fez com que assumissem estratégias de discrição e reserva em suas condutas. $\mathrm{Na}$ percepção desses sujeitos, menor visibilidade significava menor risco de se expor ao preconceito. No entanto, a estratégia do encobrimento para resistir ao preconceito e à discriminação tem seus custos, 


\section{Educere "Educare \\ Revista de EduCAČ̃̃o}

Programa de Pós-Graduação em Educação - Universidade Estadual do Oeste do Paraná

como a impossibilidade ou dificuldade de viver abertamente os relacionamentos amorosos, a necessidade de guardar segredo sobre seus sentimentos e emoções e o afastamento da rede de relações familiares.

De modo distinto, as vivências de preconceito e de discriminação podem também vir a potencializar uma posição de enfrentamento: o sujeito que experimentou intensamente essas adversidades em espaços como a rua e a vizinhança coordenava uma ONG que defendia os interesses dos homossexuais, ou seja, ocupava uma posição que proporcionava maior visibilidade à sua orientação afetivo-sexual.

As experiências de discriminação e preconceito vivenciadas por esses sujeitos na família, na escola e no ambiente religioso aconteceram antes mesmo deles se reconhecerem como homossexuais. Muitas vezes, os outros perceberam que essas pessoas eram diferentes e tentaram modificar seu modo de ser, moldar e reconfigurar suas identidades.

Ao conviverem, desde a infância, com representações implícitas e explícitas de oposição à homossexualidade, a autoestima é afetada e a aceitação de si mesmo dessas pessoas torna-se conflituosa. Algumas, antes de se assumirem, procuram adequar-se ao padrão predominante na sociedade $\mathrm{e}$ investem em relacionamentos heterossexuais. Dessa forma, antes de se reconhecerem como homossexuais precisam vencer o preconceito sexual internalizado, os sentimentos de culpa e inadequação.

Em suma, os sujeitos deste estudo foram educados numa sociedade hegemonicamente heterossexista e expostos, desde cedo, à representação de que a homossexualidade não é entendida como um modo de ser diferente, mas um desvio e até mesmo uma patologia. Constituir a identidade sexual com menos sofrimento, requeria que esses sujeitos fossem capazes de desconstruir essa representação e ressignificar a homossexualidade. Para ter condições de dar um novo significado as suas experiências no mundo, o primeiro preconceito a ser 


\section{Educere Educare \\ ReVISTA DE EduCACÃ̃o}

Programa de Pós-Graduação em Educação - Universidade Estadual do Oeste do Paraná

superado talvez seja o seu próprio preconceito. É uma situação dificil e dolorosa, visto que implica questionar e se opor ao vivido em casa, na escola, na religião, na interação com os meios de comunicação. Sentimentos de inadequação se instalaram nesses sujeitos que temiam perder o amor daqueles com quem conviviam, especialmente de seus familiares, e do próprio Deus de sua crença.

Esse processo imprimiu marcas distintas em cada um desses homens, fazendo com que a forma com que se relacionavam consigo mesmos e com o mundo fossem singulares. A forma utilizada pela maioria dos sujeitos, para resistir ao preconceito e à discriminação era o encobrimento, ou seja, manter oculta sua identidade sexual para melhor viver em sociedade. O próprio encobrimento, contudo, mostrava nuances: alguns ocultavam sua homossexualidade do maior número possivel de pessoas e outros só o faziam em momentos em que se sentiam expostos à discriminação.

Acreditamos que ainda há um grande caminho a percorrer para que a sociedade supere a homofobia impregnada nas religiões. No entanto, alguns passos já foram dados nesta direção na medida em que surgem novas agregações religiosas mais inclusivas com a comunidade LGBT e a própria Igreja Católica, através do atual papa, demonstra uma maior abertura a essas pessoas.

\section{REFERÊNCIAS}

ANTUNES, Pedro Paulo Sammarco. Homofobia internalizada: o preconceito do homossexual contra si mesmo. São Paulo, 2016. Tese. (Doutorado em Psicologia Social). Programa de Estudos Pós-graduados em Psicologia Social. Pontifícia Universidade Católica de São Paulo, 2016.

BADINTER, Elisabeth. XY; sobre a identidade masculina. 2.ed. Rio de Janeiro: Nova Fronteira, 1993.

BERNARDES, Nara Maria Guazzelli. Crianças oprimidas: autonomia e submissão. Porto Alegre, 1989. Tese. (Doutorado em Ciências Humanas e Educação). Faculdade de Educação, Universidade Federal do Rio Grande do Sul, 1989. 


\section{Educere Educare \\ ReVISTA de EduCAC̄̃o}

Programa de Pós-Graduação em Educação - Universidade Estadual do Oeste do Paraná

Análise compreendida de base fenomenológica e o estudo da experiência vivida de crianças e adultos. Educação, Revista da Faculdade de Educação da PUCRS, Porto Alegre, v. 14, n. 20, 1991. p. 15-40.

CARRARA, Sérgio, RAMOS, Sílvia. Política, direitos, violência e homossexualidade. Pesquisa 9a Parada do Orgulho GLBT - Rio 2004. Rio de Janeiro: CEPESC, 2005.

CATECISMO DA IGREJA CATÓliCA. $3^{a}$. ed. Petrópolis: Vozes; São Paulo: Paulinas, Loyola, Ave-Maria, 1993.

CECHIN, Andréa Forgiarini. Vivências em espaços educativos: constituição de identidades homossexuais em homens adultos. Porto Alegre, 2006. Tese. (Doutorado em Educação). Curso de Pós Graduação em Educação, Pontifícia Universidade Católica do Rio Grande do Sul, 2006.

HOMOSSEXUALIDADE E EDUCAÇÃO: a influência dos espaços educativos na constituição das identidades homossexuais. Curitiba: CRV, 2016.

CIAMPA, Antonio da Costa. A estória do Severino e a história da Severina: um ensaio de Psicologia Social. São Paulo: Brasiliense, 2001.

FRY, Peter, MACRAE, Edward. O que é homossexualidade. São Paulo: Brasiliense, 1983.

GIORGI, Amedeo. A psicologia como ciência humana: uma abordagem de base fenomenológica. Belo Horizonte: Interlivros, 1978.

Sketch of a psychological phenomenological method. In: GIORGI, Amedeo. Phenomenology and psychological research. Pittsburg, Duquesne University, 1985. p. $9-22$.

Método psicológico fenomenológico: alguns tópicos teóricos e práticos. Educação - Revista da Faculdade de Educação da PUCRS, Porto Alegre, v. 24, n. 43, 2001. p. 133-150.

GREEN, James Naylor. Além do carnaval: a homossexualidade masculina do século XX. São Paulo: Editora UNESP, 2000.

JACQUES, Maria da Graça. Identidade. In: STREY, Marlene, JACQUES, Maria da Graça, BERNARDES, Nara Maria Guazzelli. Psicologia social contemporânea: livro texto. Petrópolis, RJ: Vozes, 1998. p. 159-167. 


\section{Educere Educare \\ RevisTA De EduCAC̄̃̃o}

Programa de Pós-Graduação em Educação - Universidade Estadual do Oeste do Paraná

LÜDKE, Menga, ANDRÉ, Marli E. D. A. Pesquisa em Educação: abordagens qualitativas. São Paulo: EPU, 1986.

MERLEAU-PONTY, Maurice. Fenomenologia da Percepção. Rio de Janeiro: Livraria Freitas Bastos, 1971.

MYERS, D. G. Preconceito: o ódio ao próximo. In: Psicologia Social. Rio de Janeiro: LTC, 2000. p. $181-206$.

NATIVIDADE, Marcelo Tavares. Uma homossexualidade santificada?: Etnografia de uma comunidade inclusiva pentecostal. Religião e Sociedade, Rio de Janeiro, v. 30, n. 2, p. 90-121, 2010.

NATIVIDADE, Marcelo Tavares, OLIVEIRA, Leandro de. Sexualidades ameaçadoras: religião e homofobia(s) em discursos evangélicos conservadores. In: Sexualidad, Salud y Sociedad. Revista Latinoamericana. n. 02. 2009. p. 121 $-161$

NUNAN, Adriana. Homossexualidade: do preconceito aos padrões de consumo. Rio de Janeiro: Caravansarai, 2003.

Homossexualidade e discriminação: o preconceito sexual internalizado. Rio de Janeiro, 2007. Tese. (Doutorado em Psicologia). Curso de Pós Graduação em Psicologia Clínica, Pontificia Universidade Católica do Rio de Janeiro, 2007.

RANKE-HEINEMANN, Uta. Eunucos pelo Reino de Deus. São Paulo: Rosa dos Tempos, 1999.

RIBEIRO, Laura Moraes; SCORSOLINI-COMIN, Fabio. Relações entre religiosidade e homossexualidade em jovens adultos religiosos. Psicologia e Sociedade, Belo Horizonte, v. 29, dez, 2017.

SILVA, Fabiana de Sousa Castelo Branco de Melo. Um corpo estranho no santuário: discursos institucionais e experiências de indivíduos homossexuais entre pentecostais, neopentecostais e carismáticos católicos. In: SOCIAIS E HUMANAS. Santa Maria, v. 25, n. 1, jan./jun. 2012, p. $109-122$.

SILVEIRA, Carlos José Borges. Sexualidade e Gênero na Revista Mundo Jovem. Anais do Seminário Internacional Fazendo Gênero 7: gênero e preconceito. Universidade Federal de Santa Catarina - UFSC, Florianópolis, 2006.

SURANSKY, Valerie P. Phenomenology: an alternative research paradigm and a force for social change. Ann Arbor: University of Michigan, 1977. 


\section{Educere "Educare \\ RevisTA De EduCAC̄̃̃o}

Programa de Pós-Graduação em Educação - Universidade Estadual do Oeste do Paraná

TREVISAN, João Silvério. Devassos no Paraíso; a homossexualidade no Brasil, da colônia à atualidade. 5. ed. rev. ampl. Rio de Janeiro: Record, 2002.

VALLE, Edênio. A Igreja Católica ante a Homossexualidade: Ênfases e Deslocamentos de Posições. In: REVER. Revista de Estudos da Religião, PUCSP, São Paulo, n. 1, 2006. p. 153-185.

\footnotetext{
' Um dos sete sacramentos da Igreja Católica em que se confirma a escolha por esta religião.

ii Todas as falas dos participantes da pesquisa são apresentadas em itálico. Essa opção serve para diferenciá-los das citações.
}

Recebido em: 30/05/2018

Aprovado em: 20/02/2019 